\title{
Effects of Sophora japonica flowers (Huaihua) on cerebral infarction
}

\author{
Hsiang-Ni Chen ${ }^{1}$, Ching-Liang Hsieh ${ }^{1,2,3^{*}}$
}

\begin{abstract}
The dried flowers and buds of Sophora japonica are used as a medicinal herb in China, Japan and Korea to treat bleeding hemorrhoids and hematemesis. This article presents an overview of the effects of Sophora japonica on cerebral infarction based on literature searched from Medline, PubMed, Cochrane Library and the China National Knowledge Infrastructure (CNKI). Sophora japonica contains both anti-hemorrhagic and anti-hemostatic substances. Sophora japonica reduces cerebral infarction partly as a result of its anti-oxidative and anti-inflammatory activities. Previous studies found that Sophora japonica reduced the size of cerebral infarction and neurological deficits and reduced microglial activation, interleukin- $1 \beta$ release and number of apoptotic cells in ischemia-reperfusion injured Sprague-Dawley rats. Further study is required to determine the relationship between Sophora japonica-mediated reduction in cerebral infarction size and the effects of Sophora japonica on platelet aggregation and cardiovascular function.
\end{abstract}

\section{Background}

Dried flowers and buds of Sophora japonica (Huaihua) are a medicinal herb used in China, Japan and Korea to treat hemorrhoids and hematemesis [1]. Main components of Sophora japonica include flavones, tetraglycosides, isoflavones, isoflavone tetraglycosides, triterpene glycosides, phospholipids, alkaloids, amino acids and polysaccharides [2]. Moreover, Sophora japonica contains five main flavonoids of rutin, quercetin, isorhamnetin, isorhamnetin, genistein and kaempferol [2].

This article aims to provide an overview of the pharmacology of Sophora japonica, in particular its effects and mechanisms in reducing cerebral infarction (Table 1). To this end, we searched the English language databases namely Medline, PubMed, Cochrane Library and Chinese language database namely China National Knowledge Infrastructure (CNKI) between 1980 and 2009, using Sophora japonica (OR quercetin OR rutin) AND cerebral infarction as the English keywords and Huaihua as the Chinese one. The initial search generated 173 articles from the English language databases and 141 articles from the Chinese one.

\footnotetext{
* Correspondence: clhsieh@mail.cmuh.org.tw

${ }^{1}$ Department of Chinese Medicine, China Medical University Hospital,

Taichung 40402, Taiwan

Full list of author information is available at the end of the article
}

\section{Pharmacology \\ Anti-oxidative effects}

Our previous studies found that (1) levels of superoxide anion in arterial blood increased at the start of 2 hours of reperfusion after ischemia in rats with middle cerebral artery occlusion (MCAo) [3]; (2) levels of superoxide anion in the region of brain parenchymal damage increased during 2 hours of reperfusion after cerebral ischemia in ischemia-reperfusion injured rats [4]; (3) Guizhifuling Wan (consisting of Cinnamon twig, Prunus persica [L] Batsch, Poria cocos [Schw.] Wolf, Paeonia lactiflora Pall, Paeonia suffruticosa Andr, Angelica sinensis [Oliv. Diels and Ligusticum chuanxiong Hort.] with ferulic acid and Paeonia suffruticosa with paeonol as components and the root of Paeonia lactflora Pall) reduced superoxide anion levels during 2 hours of reperfusion after ischemia, cerebral infarction size and neurological deficit score in rats with MCAo [3-5]. Free radical scavenging activity was demonstrated in Ginkgo biloba L. leaves which contain quercetin and rutin which have free radical scavenging activity [6]. Extracts of Ginkgo biloba L. leaves (Egb 761) reduced the size of cerebral infarction and improved neurological behavior in rats with permanent and transient MCAo [7]. Ma et al. found that the flavonoid components of Sophora japonica scavenged superoxide anion and 1,1-diphenyl-2-picrylhydrazyl (DPPH) free radicals [8]. Simple and orthogonal experiments to study the 
Table 1 Possible pharmacological actions of Sophora japonica on cerebral infarction

\begin{tabular}{|c|c|c|}
\hline Pharmacological actions & Related components & Possible mechanisms \\
\hline \multirow[t]{5}{*}{ Anti-oxidative effects } & flavonoid & scavenges superoxide anion and free radicals [8] \\
\hline & polysaccharides & scavenges hydroxyl and superoxide anion free radicals [9] \\
\hline & quercetin and rutin & scavenge free radicals $[10]$ \\
\hline & rutin & inhibits the conversion of superoxide anion to hydroxyl radicals [11] \\
\hline & irisolidone & $\begin{array}{l}\text { inhibits lipid peroxidation, DNA damage, and reduced apoptosis induced by } \\
\text { hydrogen peroxide [12] }\end{array}$ \\
\hline \multirow[t]{2}{*}{ Anti-inflammatory effects } & quercetin and rutin & inhibit microglial activation, interleukin-1 $\beta$ (IL-1 $\beta$ ) release, and apoptosis [25] \\
\hline & rutin & reduce IL-1 $\beta$ mRNA expression [26] \\
\hline \multirow[t]{2}{*}{$\begin{array}{l}\text { Anti-platelet aggregation } \\
\text { effects }\end{array}$} & $\begin{array}{l}\text { biochanin } A \text {, irisolidone, genistein and } \\
\text { tectoridin }\end{array}$ & inhibit arachidonic acid- and thromboxane $\mathrm{A}_{2}$ - induced platelet aggregation [2] \\
\hline & quercetin & inhibits free calcium increase within platelets [27] \\
\hline \multirow[t]{4}{*}{ Cardiovascular effects } & Sophora japonica decoction & reduces cardiac muscle contractility and reduces heart rate $[30,31]$ \\
\hline & Quercetin & stabilizes capillary integrity [32] \\
\hline & rutin, quercetin and tannin & reduce capillary perameability $[31,33]$ \\
\hline & Isorhamnetin & increases capillary permeability [1] \\
\hline
\end{tabular}

antioxidative activites of Sophora japonica, Wang et al. found that the polysaccharides of Sophora japonica scavenged hydroxyl and superoxide anion free radicals [9]. Both quercetin and rutin demonstrated free radical scavenging activity; however, quercetin offered better protection. A study reported that quercetin (better than rutin) protected rabbit erythrocytes with normal and high cholesterol content against lipid peroxidation by $t-\mathrm{BuOOH}-$ induced reactive oxygen species [10]. Afanas'ev et al. found that rutin in iron-rutin complex inhibited the conversion of superoxide anion to hydroxyl radicals in normal and iron-overloaded rats [11]. Kang et al. showed that the anti-oxidant irisolidone prevented lipid peroxidation, DNA damage and reduced apoptosis induced by hydrogen peroxide in Chinese hamster lung fibroblasts [12].

Generation of reactive oxygen species (ROS) including nitrogen and oxygen free radicals played a critical role in brain damage during the reperfusion period after ischemia $[13,14]$. Brain damage due to ROS-mediated injury involved metabolic signal transmission among mitochondria, DNA repair enzymes and transcription factors leading to apoptosis [15]. Anti-oxidant components such as those in Gingko biloba extracts played a neuroprotective role $[16,17]$. Both quercetin and rutin scavenged free radicals, improved spatial memory and reduced neuronal death induced by repeated cerebral ischemia [18]. Rutin reduced ischemia-reperfusion injury by scavenging reactive species $[14,19]$.

\section{Anti-inflammatory effects}

Microglia was activated by various types of brain damage such as ischemic and inflammatory damage [20]. This activation indicated the severity of neuronal damage in rats with MCAo [21]. The levels of IL-1 $\beta$, a pro-inflammatory cytokine which is expressed mainly by glial cells such as astrocytes, oligodendrocytes and microglia [22] increased after permanent focal cerebral ischemia [23] whereas they reduced leucocyte infiltration, thereby causing neuronal damage and brain edema [24]. Similarly, our previous studies found that both Guizhifuling Wan and paeonol inhibited microglial activation and IL-1 $\beta$ release and reduced cerebral infarction size in rats with MCAo [3,5]. Sophora japonica inhibited microglial activation, interleukin- $1 \beta$ (IL-1 $\beta$ ) release and apoptosis in rats with transient MCAo, suggesting that Sophora japonica reduced inflammation and prevented neuronal death by inhibiting microglial release of IL-1 $\beta$, a pro-inflammatory cytokine [25]. Koda et al. reported that dietary rutin supplementation 10 or 20 days after trimethyltin (TMT) administration in rats reduced IL- $1 \beta$ mRNA expression in the microglia of the hippocampus, suggesting that rutin was neuro-protective against TMT-induced neuronal damage [26].

\section{Anti-platelet aggregation effects}

Kim and Yun-Chol reported that, compared with acetylsalicylic acid, biochanin A, irisolidone, genistein and tectoridin of Sophora japonica were stronger inhibitors of arachidonic acid- and thromboxane $\mathrm{A}_{2}$-induced platelet aggregation in platelet-rich and platelet-poor plasma in rats [2]. A study found that quercetin of Sophora japonica inhibited free calcium accumulation within platelets thereby preventing platelet aggregation [27]. Antiplatelet agents such as aspirin were recommended for the treatment of acute ischemic stroke [28]. Platelet adhesion was enhanced after MCAo and reperfusion in mice [29]. 


\section{Effects on cardiovascular system and blood coagulation} Administration of Sophora japonica decoction into the jugular veins of rabbits decreased cardiac muscle contractility and reduced heart rate, suggesting that Sophora japonica reduced the consumption of oxygen to protect cardiac function [30,31]. The anti-hemorrhagic effect of quercetin (water extracts of the buds of Sophora japonica) was due to stabilization of capillary integrity [32]. Oral administration of Sophora japonica extracts (containing rutin, quercetin and tannin) for five days reduced capillary perameability, bleeding time and coagulation time in mice and reduced prothrombin time in rats, thereby demonstrating the hemostatic effect of Sophora japonica [30,33]. Isorhamnetin from Sophora japonica was also anti-hemostatic, as a result from increased capillary permeability and reduced platelet aggregation [1].

\section{Conclusion}

Sophora japonica contains both anti-hemorrhagic and anti-hemostatic substances. Sophora japonica reduces cerebral infarction partly as a result of its anti-oxidative and anti-inflammatory activities. Further study is required to determine the relationship between Sophora japonica-mediated reduction in cerebral infarction size and its effects on platelet aggregation and cardiovascular function.

\section{Abbreviations}

MCAO: middle cerebral artery occlusion; EGB 761: extract of Ginkgo biloba L. leaves; DPPH: 1,1-diphenyl-2-picrylhydrazyl; T-BUOOH: tert-butyl hydroperoxide; IL-1 $\beta$ : interleukin-1 $\beta$; TMT: trimethyltin; MRNA: messenger ribonucleic acid; ROS: reactive oxygen species; DNA: deoxyribonucleic acid.

\section{Acknowledgements}

We thank the Chinese Medicine Editorial Team for their valuable comments. This study was supported in part by the Department of Health Clinical Trial (Taiwan) and Research Center of Excellence (DOH99-TD-B-111-004).

\section{Author details}

${ }^{1}$ Department of Chinese Medicine, China Medical University Hospital, Taichung 40402, Taiwan. ${ }^{2}$ Graduate Institute of Acupuncture Science, China Medical University, Taichung 40402, Taiwan. ${ }^{3}$ Acupuncture Research Center, China Medical University, Taichung 40402, Taiwan.

\section{Authors' contributions}

$\mathrm{CLH}$ designed the study and revised the manuscript. HNC conducted the literature search and drafted the manuscript. Both authors read and approved the final version of the manuscript.

\section{Competing interests}

The authors declare that they have no competing interests.

Received: 22 March 2010 Accepted: 27 September 2010 Published: 27 September 2010

\section{References}

1. Ishida H, Umino T, Tsuji K, Kosuge T: Studies on the antihemostatic substances in herbs classified as hemostatics in traditional Chinese medicine. I. On the antihemostatic principles in Sophora japonica L. Chem Pharm Bull (Tokyo) 1989, 37:1616-1618.
2. Kim JM, Yun-Choi HS: Anti-platelet effects of flavonoids and flavonoidglycosides from Sophora japonica. Arch Pharm Res 2008, 31(7):886-890.

3. Hsieh CL, Cheng CY, Tsai TH, Lin IH, Liu CH, Chiang SY, Lin JG, Lao CJ, Tang NY: Paeonol reduced cerebral infarction involving the superoxide anion and microglia activation in ischemia-reperfusion injured rats. J Ethnopharmacol 2006, 106:208-215.

4. Cheng CY, Ho TY, Lee EJ, Su SY, Tang NY, Hsieh CL: Ferulic acid reduces cerebral infarction through its antixidative and anti-inflammatory effect following transient focal cerebral ischemia in rats. Am J Chin Med (Gard City NY) 2008, 36(6):1105-1119.

5. Hsieh CL, Ho TY, Su SY, Cheng CY, Hsu WT, Hsieh CT, Pu HY, Tang NY: GuiZhi-Fu-Ling-Wan reduces cerebral infarction area via the antiinflammatory effects in ischemia-reperfusion injured rats. Mid Taiwan J Med 2008, 13:1-11.

6. Ellnain-Wojtaszek M, Kruczyński Z, Kasprak J: Investigation of the free radical scavenging activity of Ginkgo biloba L. leaves. Fitoterapia 2003, 74:1-6.

7. Lee EJ, Chen HY, Wu TS, Chen TY, Ayoub IA, Kenneth I, Maynard MJ: Acute administration of Ginkgo biloba extract (EGb761) affords neuroprotection against permanent and transient focal cerebral ischemia in Spragrue-Dawley rats. J Neurosci Res 2002, 68:636-645.

8. Ma LH, He JP, Qin WD, Wang P, Liu HY: Study on anti-oxidative activities of pogadatree flower (Robinia Pseudocacia) extracts. Food Sci 2007, 28(9):75-77, [In Chinese].

9. Wang LH, Duan YF, Ma YL, Ding HJ, Li EC: Studies on extraction and antioxidant function of polysaccharides from sophora japonica. J Northwest A \& F (Nat Sci Ed) 2008, 36(8):213-218, [In Chinese].

10. López-Revuelta A, Sánchez-Gallego J, Hernández-Hernández A, SánchezYagüe J, Marcial Llanillo M: Membrane cholesterol contents influence the protective effects of quercetin and rutin in erythrocytes damages by oxidative stress. Chem Biol Interact 2006, 161:79-91.

11. Afanas'ev IB, Ostrachovitch EA, Abramova NE, Korkina LG: Different antioxidant activities of bioflavonoid rutin in normal and iron overloading rats. Biochem Pharmacol 1995, 50:627-635.

12. Kang KA, Zhang R, Piao MJ, Ko DO, Wang ZH, Kim BJ, Park JW, Kim HS, Kim DH, Hyun JW: Protective effect of irisolidone, a metabolite of kakkalide, against hydrogen peroxide induced cell damage via antioxidant effect. Bioorg Med Chem 2008, 16:1133-1141.

13. Love S: Oxidative stress in brain ischemia. Brain Pathol 1999, 9, 119,131.

14. Gursoy-Ozdemir Y, Can A, Dalkara T: Reperfusion -induced oxidative/ nitrative injury to neurovascular unit after focal cerebral ischemia ischemia. Stroke 2004, 35:1449-1453.

15. Chan PH: Reactive oxygen radicals in signaling and damage in the ischemic brain. J Cereb Blood Flow Metab 2001, 21:2-14.

16. Clark WM, Rinker LG, Lessov NS, Lowery SL, Cipolla MJ: Efficacy of antioxidant therapies in transient focal ischemia in mice. Stroke 2001, 32:1000-1004

17. Ikeda K, Negishi H, Yamori Y: Antioxidant nutrients and hypoxia/ischemia brain injury in rodents. Toxicology 2003, 189:55-61.

18. Pu F, Mishima K, Irie K, Motohashi K, Tanaka Y, Orito K, Takashi E, Kitamura Y, Egashira N, Iwasaki K, Fujiwara M: Neuroprotective effects of quercetin and rutin on spatial memory impairment in an 8-arm radial maze task and neuronal death induced by repeated cerebral ischemia in rats. J Pharmacol Sci 2007, 104:329-334.

19. Gupta R, Singh M, Sharma A: Neuroprotective effect of antioxidants on ischaemia and reperfusion-induced cerebral injury. Pharmacol Res 2003, 48:209-213.

20. Korematsu K, Goto S, Nagahiro S, Ushio Y: Microglial response to transient focal cerebral ischemia: an immunochemical study on the rat cerebral cortex using anti-phosphotysine antibody. J Cereb Blood Flow Metab 1994, 14:825-830.

21. Morioka T, Kalehua AN, Streit WJ: The microglial reaction in the rat dorsal hippocampus following transient forebrain. J Cereb Blood Flow Metab 1991, 11:966-973.

22. Sairanen TR, Lindsberg PJ, Brenner M, Sirén AL: Global forebrain ischemia results in differential cellular expression of interleukin-1 $\beta$ (IL-1 $\beta)$ and its receptor at mRNA and protein level. J Cereb Blood Flow Metab 1997, 17:1107-1120.

23. Liu T, McDonnell PC, Young PR, White RF, Siren AL, Hallenbeck JM, Barone FC, Feuerstein GZ: Interleukin-1 $\beta$ mRNA expression in ischemia rat cortex. Stroke 1993, 24:1746-1751. 
24. Yamasaki Y, Matsuura N, Shozuhara H, Onodera H, Itoyama Y, Kohure K: Interleukin-1 as a pathogenetic mediator of ischemic brain damage in rats. Stroke 1995, 26:676-681.

25. Lao CJ, Lin JG, Kuo JS, Lee Chao PD, Cheng CY, Tang NY, Hsieh CL: Microglia, apoptosis and interleukin-1 $\beta$ expression in the effect of Sophora Japonica L. on cerebral infarct induced by ischemia-reperfusion in rats. Am J Chin Med (Gard City NY) 2005, 33(3):425-438.

26. Koda $T$, Kuroda $Y$, lami $H$ : Rutin supplementation in the diet has protective effects against toxicant-induced hippocampal injury by suppression of microglial activation and pro-inflammatory cytokines. Cell Mol Neurobiol 2009, 29:523-531.

27. Chi YP: Pharmacological Action and Application of Blood-Activating and Stasis-Eliminating Available Composition of Traditional Chinese Medicine Harbin: Heilungkiang Science and Technology Publisher, 11999:225-228.

28. Bednar MM, Gross CE: Antiplatelet therapy in acute cerebral ischemia. Stroke 1999, 30:887-893.

29. Terao S, Yilmaz G, Stokes KY, Russell J, Ishikawa M, Kawase T, Granger DN: Blood cell-derived RANTES mediates cerebral microvascular dysfunction, inflammation, and tissue injury after focal ischemia-reperfusion. Stroke 2008, 39:2560-2570.

30. Wang T, Xue K, Yang S: Effects of decocted flos sophorae solution on hemodynamics in anesthetized rabbit. ACMP 2001, 29(1):40-42, [In Chinese].

31. Wu H, Lan C, Chen Y: Study development of sophora japonica. Guangdong Weiliang Yuansu Kexue 2006, 13(6):1-5, [In Chinese].

32. Ishida $H$, Umino T, Tsuji K, Kosuge T: Studies on antihemorrhagic substances in herbs classified as hemostatics in Chinese medicine. VI. On the antihemorrhagic principle in Sophora japonica L. Chem Pharm Bull (Tokyo) 1987, 35(2):857-60.

33. Li H, Yuan GD, Jin YH: Experimental study on hemostatic effect of flos sophorae and its extracts. Zhongguo Zhongxiyi Jiehe Zazhi 2004, 24(11):1007-1009, [In Chinese].

doi:10.1186/1749-8546-5-34

Cite this article as: Chen and Hsieh: Effects of Sophora japonica flowers (Huaihua) on cerebral infarction. Chinese Medicine 2010 5:34.

\section{Submit your next manuscript to BioMed Central and take full advantage of:}

- Convenient online submission

- Thorough peer review

- No space constraints or color figure charges

- Immediate publication on acceptance

- Inclusion in PubMed, CAS, Scopus and Google Scholar

- Research which is freely available for redistribution

Submit your manuscript at www.biomedcentral.com/submit
Biomed Central 